\title{
Comparative analysis of the location of rDNA in the Palaearctic bushcricket genus Isophya (Orthoptera: Tettigoniidae: Phaneropterinae)
}

\author{
BEATA GRZYWACZ ${ }^{1}$, ANNA MARYAŃSKA-NADACHOWSKA ${ }^{1}$, DRAGAN P. CHOBANOV ${ }^{2}$, TATJANA \\ KARAMYSHEVA $^{3}$ and ELŻBIETA WARCHAŁOWSKA-ŚLIWA ${ }^{1}$ \\ ${ }^{1}$ Institute of Systematics and Evolution of Animals, Polish Academy of Sciences, Kraków, Poland; \\ e-mail: grzywacz@isez.pan.krakow.pl \\ ${ }^{2}$ Institute of Biodiversity and Ecosystem Research, Bulgarian Academy of Sciences, Sofia, Bulgaria \\ ${ }^{3}$ Institute of Cytology and Genetics, Siberian Branch of the Russian Academy of Sciences, Novosibirsk, Russia
}

Key words. Orthoptera, FISH, Ag-NOR, rDNA, telomeric repeats

\begin{abstract}
The present study focused on the evolution of the karyotype in 21 taxa of the genus Isophya, which was done by mapping the location on the chromosomes of ribosomal RNA (rRNA) coding genes using fluorescence in situ hybridization (FISH) with an $18 \mathrm{~S}$ rDNA probe and using silver staining $\left(\mathrm{AgNO}_{3}\right)$ to evaluate the activity of major rDNA clusters. Since the chromosome number and sex determination do not vary in this genus, the above markers were used in a detailed comparison of the cytogenetic features of species of Isophya. The species analyzed were placed into three groups based on the location of rDNA on their chromosomes: (1) rDNA-FISH signals only on the two long pairs of autosomes, (2) rDNA-FISH signals on one long and one short pair of autosomes, and (3) rDNA-FISH signals on three to five different sized pairs of autosomes. These groupings partly correspond to the morphological groupings proposed in earlier studies. One long pair of autosomes frequently carried rDNA in all the Isophya species and probably is a plesiomorphic character for these taxa. The cytogenetic mapping revealed great variability among Isophya species in the chromosomal location of major rDNA clusters. Our results suggest that the observed variation in the number of rDNA clusters can be an important species-group specific phylogenetic marker. Analysis of 18S rDNA hybridization signals showed that the evolutionary dynamics of rDNA in this genus is remarkably high and accompanied by changes in the structure of chromosomes bearing rDNA at an inter- and intra-specific level. The telomeric sequence (TTAGG) ${ }_{n}$ hybridized with the termini of most of chromosomes, however, some chromosome ends lacked signals probably due to a low copy number of telomeric repeats.
\end{abstract}

\section{INTRODUCTION}

The genus Isophya Brunner von Wattenwyl (1878) is one of the largest bushcricket genera in including 89 species (Eades et al., 2011) (I. medimontana Nedelkov, 1907 is actually regarded as a subspecies by Harz, 1969). It occurs in Central Europe, the Carpathian Basin, the Balkans, southern Ukraine, Asia Minor and the Caucasus region, eastwards reaching north western Iran and Iraq and an isolated area of the Altai Mountains (Bey-Bienko, 1954). Most species of Isophya have restricted ranges and thus the genus includes a high number of endemic taxa (Sevgili, 2003; Sevgili \& Heller, 2003). The status of many species remains unresolved because Isophya contains several morphologically very similar species (Heller, 1988, 2006; Warchałowska-Śliwa et al., 2008; Chobanov, 2009a, b). In spite of the existing comprehensive bioacoustic and morphological (e.g. Heller et al., 2004; Sevgili et al., 2006), classical cytogenetic (e.g. Warchałowska-Śliwa et al., 2008) and molecular studies (Grzywacz \& Warchałowska-Śliwa, 2008; GrzywaczGibała et al., 2010), the relationships within the group are still poorly known. The development of new cytogeneticmolecular markers is important for a better understanding of the genome organization and phylogeny of this genus.

Over 25 species and subspecies of Isophya have been studied cytotaxonomically (Warchałowska-Śliwa et al.,
2008). The majority of these species have a karyotype consisting of $2 \mathrm{n}=31$ (male) / 32 (female) acrocentric chromosomes with an X0/XX mechanism of sex determination. This karyotype is suggested as ancestral for most species of tettigoniids (e.g. White, 1973; WarchałowskaŚliwa, 1998). Only one species, I. hemiptera (from the northern Caucasus), has a neo-X/neo-Y sex determination system (Warchałowska-Śliwa \& Bugrov, 1998). Thus, the species of this genus have the same number of chromosomes and sex determination system. In the sex chromosome $(\mathrm{X})$, the most remarkable changes include a pericentric inversion that converted the ancestral acrocentric $\mathrm{X}$ into a subacro/submetacentric $\mathrm{X}$. Inter-specific autosomal differentiation involved the distribution and quantity of $\mathrm{C}$-heterochromatin and the number of nucleolar organizer regions (NORs), thus revealing discrete changes that reflect the level of genomic organization (Warchałowska-Śliwa et al., 2008).

Recently, fluorescence in situ hybridization (FISH) techniques were extensively used for mapping DNA sequences directly on chromosomes, which has significantly increased our understanding of karyotype structure and evolution. In particular, major ribosomal RNA (rRNA) genes, the so-called rDNA, clustered in the nucleolar organizer regions (NORs) have been found useful as markers for karyotype comparisons in many insect species at the genus level, e.g. tiger beetles (Zacaro 
et al., 2004), grasshoppers (e.g. Loreto et al., 2008) and bushcrickets (Warchałowska-Śliwa et al., 2009). Other repetitive sequences, the so-called telomeric DNA, are located mainly at chromosome termini. Telomeres were used as markers for identifying the ends of chromosomes and in the majority of insect orders, including Orthoptera, are composed of multiple copies of short, tandemly arranged TTAGG sequences. Clusters of telomeric repeats are thought to indicate chromosomal rearrangements related to changes in chromosome number and evolution in insects (López-Fernández et al., 2004, Warchałowska-Śliwa et al., 2009).

The stable karyotype of Isophya species and other short-winged species belonging to different genera of the tribe Barbitistini, namely Ancistrura, Andreiniimon, Barbitistes, Metaplastes, Poecilimon, Polysarcus, etc. (see review Warchałowska-Śliwa, 1998), is a simple model the study of which could contribute greatly to understanding the evolutionary dynamics of rDNA. The location of rRNA genes in Phaneropterinae by FISH has so far only been done for a single species (Hemp et al., 2010). Recently, silver impregnation was used to identify NORs in 15 species of the genus Isophya (Warchałowska-Śliwa et al., 2008).

The present study reports the results of follow-up research on the reconstruction of the ancestral karyotype based on the number and distribution of rDNA clusters in 21 species/subspecies of the genus Isophya using FISH with $18 \mathrm{~S}$ rDNA probe as a potentially useful marker. In addition, NOR activity was verified by silver impregnation for 15 species previously analysed and 6 more species added for which this information was not available. A comparison of rDNA-FISH results with those after silver impregnation enabled us to identify non-active NOR clusters and precisely locate the active NORs. In all rDNA-FISH experiments, we used simultaneously a (TTAGG) $)_{n}$ probe for a better identification of chromosome ends, particularly at diplotene/ diakinesis. This study is the first on the chromosome evolution and phylogeny of Phaneropterinae bushcrickets.

\section{MATERIAL AND METHODS}

The 55 specimens analyzed represent 21 taxa of the genus Isophya. Adults or nymphs were collected during June/July from 2006 to 2010 in Bulgaria, Poland, Germany, Serbia and Russia (for localities see Table 1).

Gonads of the specimens were dissected out, treated with a hypotonic solution $(0.9 \%$ sodium citrate $)$ and then fixed in Carnoy (3 : 1 ethanol : acetic acid). Chromosome preparations were made by macerating cellular suspensions in drops of $45 \%$ acetic acid on slides, which were then squashed under cover slips. Then the cover slips were removed by the dry ice procedure and the slides air dried. The C-banding was carried out according to Sumner (1972) with a slight modification. The silver staining method $\left(\mathrm{AgNO}_{3}\right)$ for visualising NORs was applied as previously reported (Warchałowska-Śliwa \& Maryańska-Nadachowska, 1992).

\section{Fluorescence in situ hybridization with $18 \mathrm{~S}$ rDNA} (rDNA-FISH) and (TTAGG) ${ }_{n}$ telomeric probes

For rDNA-FISH, a $1.8 \mathrm{~kb}$ fragment of $18 \mathrm{~S}$ rDNA was generated by PCR using genomic DNA isolated from Isophya ram- mei (Orthoptera) as a template. The amplification was performed in a final volume of $25 \mu 1$ containing $1.5 \mathrm{mM} \mathrm{MgCl}_{2}, 2.5$ $\mathrm{mM}$ dNTP, $10 \mu \mathrm{M}$ of each of the two primers 18 Sai forward (5'-CCT GAG AAA CGG CTA CCA CAT C-3') and 18Sbi reverse (5'-GAG TCT CGT TCG TTA TCG GA-3') (Whiting et al., 1997), $100 \mathrm{ng}$ template DNA and 5 U Taq DNA polymerase (Qiagen, Hilden, Germany). An initial period of $3 \mathrm{~min}$ at $94^{\circ} \mathrm{C}$ was followed by 30 cycles of $60 \mathrm{~s}$ at $94^{\circ} \mathrm{C}, 60 \mathrm{~s}$ at $51^{\circ} \mathrm{C}$, and 1.5 min at $72^{\circ} \mathrm{C}$ and concluded by a final extension step of $10 \mathrm{~min}$ at $72^{\circ} \mathrm{C}$. The probe was labelled by nick translation with biotin11-dUTP (Invitrogen, Tokyo, Japan).

The (TTAGG) ${ }_{n}$ telomeric probe was generated by PCR using a modified version of the López-Fernández et al. (2004) technique. PCR was performed in a $50 \mu 1$ reaction mixture containing $1.5 \mathrm{mM} \mathrm{MgCl}, 0.2 \mathrm{mM}$ each dNTP, $0.5 \mu \mathrm{M}$ of each of the two primers (5'-GGTTA-GGTTA-GGTTA-GGTTA-GG-3' and 5'-TAACC-TAACC-TAACC-TAACC-TAA-3') and 2 U Taq DNA polymerase. The non-template PCR was performed with an initial cycle of $90 \mathrm{~s}$ at $94^{\circ} \mathrm{C}$, followed by 30 cycles of 45 $\mathrm{s}$ at $94^{\circ} \mathrm{C}, 30 \mathrm{~s}$ at $40^{\circ} \mathrm{C}$ and $60 \mathrm{~s}$ at $72^{\circ} \mathrm{C}$ and a final extension step of $10 \mathrm{~min}$ at $72^{\circ} \mathrm{C}$. The PCR product was then labelled with digoxigenin-11-dUTP in additional PCR cycles.

For FISH using both the rDNA and telomeric probes, we used the procedure described in Lichter et al. (1988). Chromosome preparations were treated with $100 \mu \mathrm{g} / \mathrm{ml}$ RNase A. After denaturation the chromosomes were hybridized with a probe mixture containing $20 \mathrm{ng}$ of $18 \mathrm{~S}$ rDNA probe, the (TTAGG) ${ }_{n}$ telomeric probe and $10 \mu \mathrm{g}$ of sonicated salmon sperm DNA (Invitrogen). Hybridization signals were detected with avidin-Alexa 488 (Invitrogen) and mouse anti-digoxigenin antibodies conjugated to $\mathrm{Cy} 3$ (Sigma-Aldrich, Tokyo, Japan). The preparations were counterstained with $20 \mu 1$ DAPI (Sigma-Aldrich, Tokyo, Japan) for $15 \mathrm{~min}$ and then mounted in anti-fade based on DABCO (1-4-diazabicyclo[2.2.2]octane; Sigma-Aldrich) (see Sahara et al., 1999).

At least 15 meiotic divisions (diplotene/diakinesis) per male and two (rarely 3 ) males per species were analyzed using FISH and $\mathrm{AgNO}_{3}$ techniques. In addition, spermatogonial or oogonial metaphases for some species were examined. FISH and silver staining techniques were used on the same species to determine whether these markers gave the same results when used on specimens collected from different geographical locations (Table 1). Photographs were taken with a Nikon Eclipse 400 light microscope fitted with a CCD DS-U1 camera using Chroma filter sets (for FISH). The software Lucia Image 5.0 was applied and images were mounted in Adobe Photoshop.

\section{RESULTS}

As described elsewhere (e.g. Warchałowska-Śliwa et al., 2008 except for $I$. hemiptera), the karyotypes of all the species analyzed consist of 31 chromosomes in the male and 32 in the female with an X0/XX sex determination system. Fifteen pairs of acrocentric autosomes can be arranged into two size groups: four long (L) and eleven medium and short $(\mathrm{M} / \mathrm{S})$ pairs. The pairs gradually decrease in size resulting in some problems with the precise identification of chromosome pairs (especially among the long and short ones). The acrocentric, subacrocentric, or submetacentric $\mathrm{X}$ chromosome is the longest element in the set (Fig. 1a).

The localization of rDNA in Isophya, resolved by FISH and its activity analyzed by silver impregnation, are shown Figs 1-5 and summarized in Table 1. FISH revealed two (rarely one) to five clusters of rDNA (Fig. 


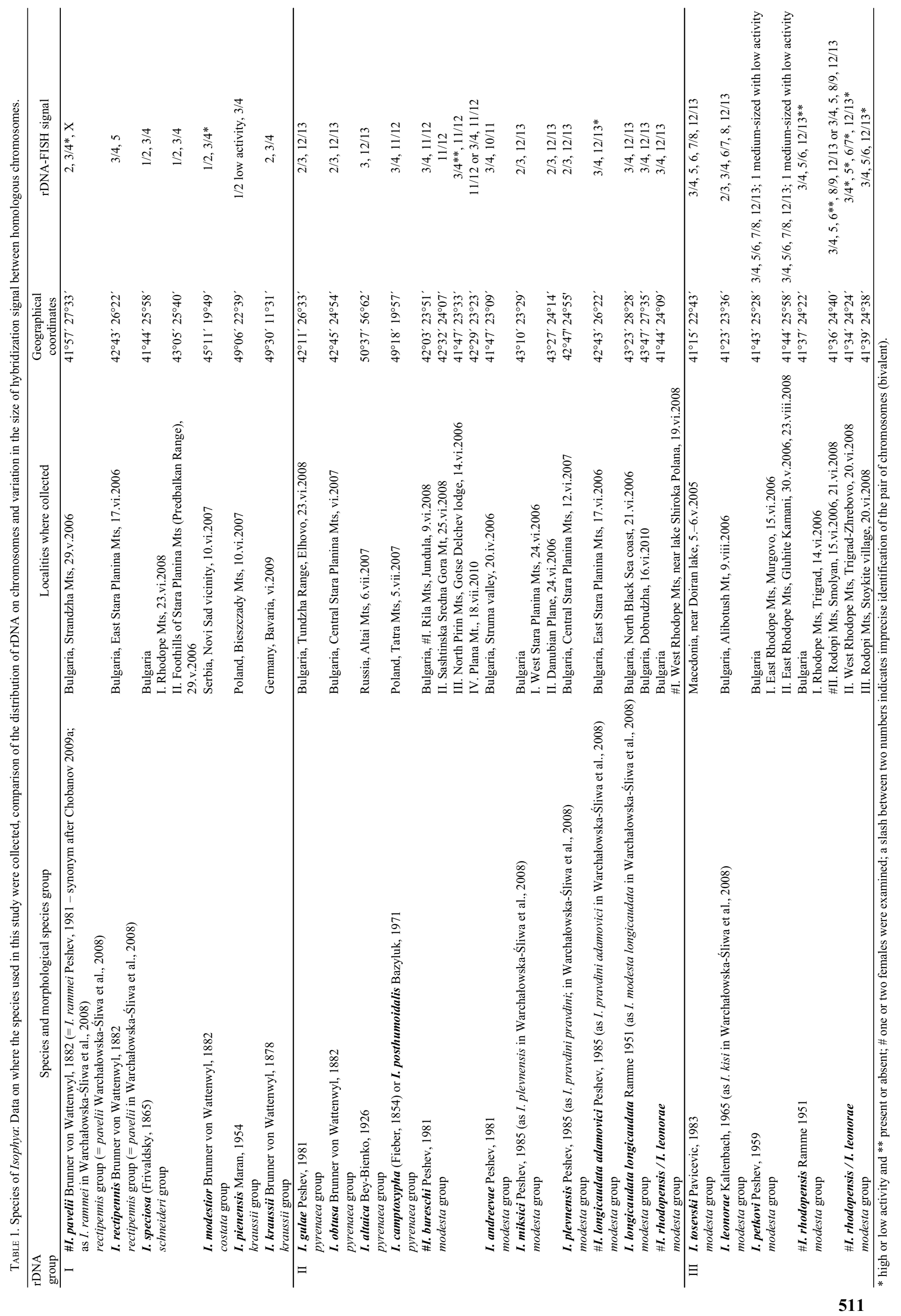




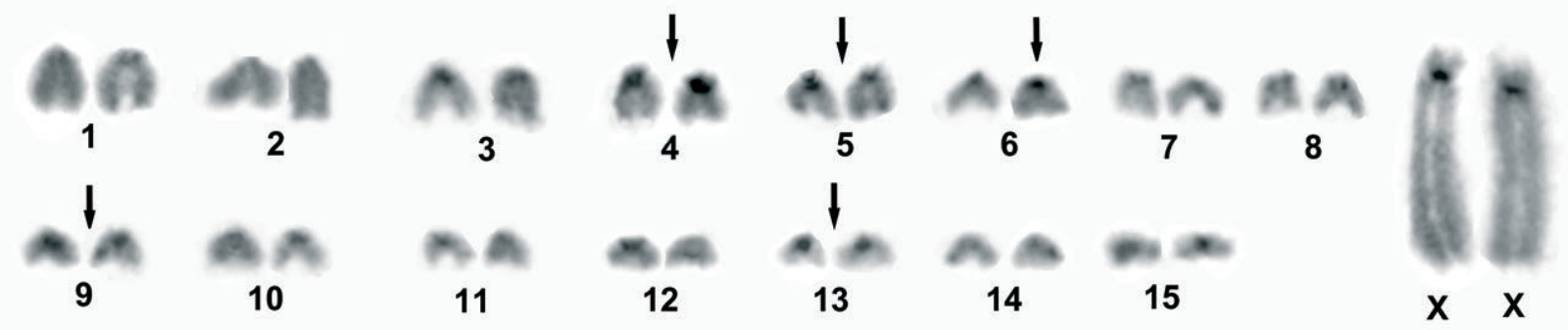

a

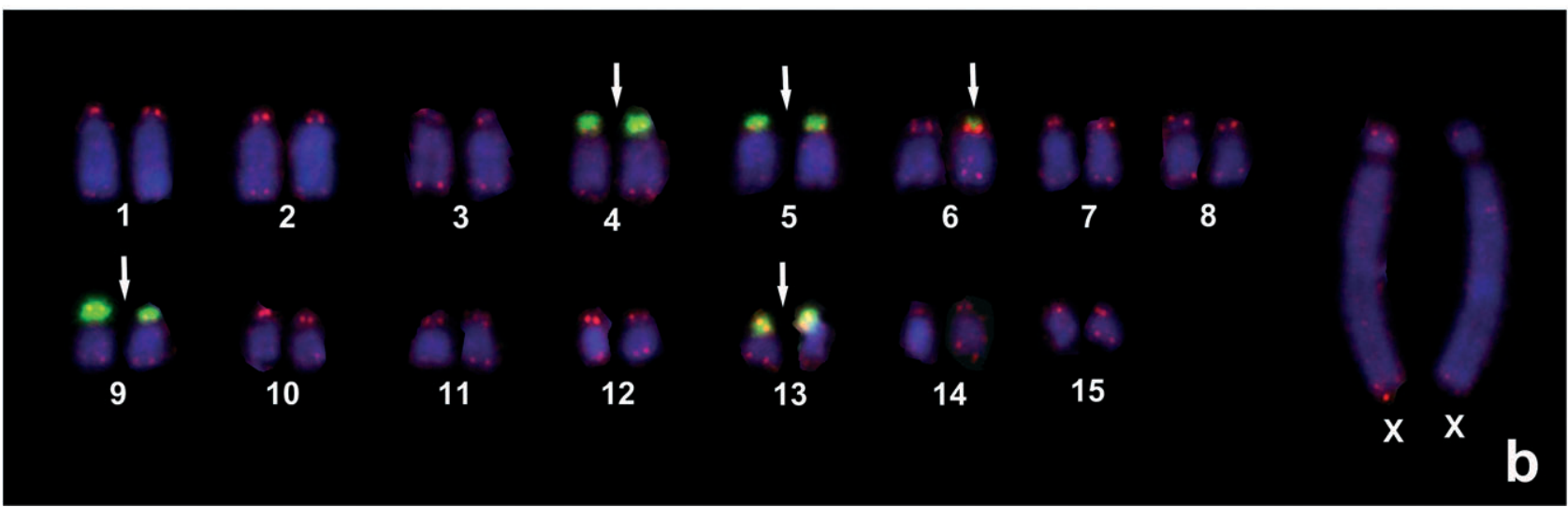

Fig. 1. C-banding staining (a) and FISH (b), using both 18S rDNA (green) and telomeric DNA (red) probes, of the karyotype of Isophya rhodopensis (Smoljan population). Arrows indicate (a) thick C-bands and (b) rDNA sites near centromeric regions of the acrocentric chromosomes. C-heterochromatin (a) and both the TTAGG and rDNA signals (b) on $\mathrm{M}_{6}$ varied between two homologous chromosomes. $\mathrm{X}$ - sex chromosome. Bar $=10 \mu \mathrm{m}$.

1b), located on the autosomes and sporadically on the $\mathrm{X}$ chromosome. The clusters were observed at meiosis from diakinesis to metaphase I on bivalents and at mitosis on the spermatogonial or oogonial metaphase chromosomes. Hybridization with rDNA probes produced an identically positioned signal at the oogonial mitotic metaphase and on the spermatogonial mitotic and meiotic chromosomes. According to the differences in number and location of $18 \mathrm{~S}$ rDNA signals, three groups are specified (Table 1) as follows.

Group I. In six species the rDNA clusters were evident on two long bivalents at diplotene/diakinesis and four autosomes at mitotic metaphase (Fig. 2a-d). They are located near the centromeric regions of the autosomes (probably $1^{\text {st }}$ or $2^{\text {nd }}-1 / 2$ and $3^{\text {rd }}$ or $4^{\text {th }}-3 / 4$ ) of $I$. pavelii (Fig. 2a), I. speciosa (both populations), I. modestior (Fig. 2b), I. pienensis and I. kraussii, and distal to the centromere on $3 / 4$ and $5^{\text {th }}$ in I. rectipennis (Fig. $2 \mathrm{c}, \mathrm{d}$ ). Additionally, a low intensity rDNA-FISH signal near the centromeric region of the sex chromosome was observed in I. pavelii (Fig. 2a).

Group II. Eleven species carried rDNA on a pair of long (probably 3/4) and a pair of short chromosomes (probably 11,12 or 13 ) always near the centromeric regions (Fig. 3a, b). Intra-specific variation in this pattern was found in $I$. bureschi. Individuals collected from two populations (Rila Mts and Pirin Mts) revealed signals on two autosomal pairs - long and short (L and S) autosomes, whereas one population (Sastinska Sredna Gora Mt.) showed a hybridization signal only on one pair of short chromosomes (Fig. 3d, e). In addition, only one out of four individuals collected on Plana Mt. (between the two mentioned regions) possessed extra rDNA sequences on the long bivalent.

Group III. In this group FISH revealed rDNA only near the centromeric region on three or four bivalents, differing in size, of both populations of I. petkovi (Fig. 4a) and on five bivalents of I. leonorae and I. tosevski (Fig. 4b). Analysis of $I$. rhodopensis and individuals determined as I. rhodopensis/leonorae collected from different populations showed variation in the position of $18 \mathrm{~S}$ rDNA on three to five pairs of chromosomes (Fig. 1b).

In some species comparisons, the rDNA-carrying chromosomes differed in the size of the hybridization signal on different autosomes. For example, in I. camptoxypha the rDNA hybridization signal varied between autosomes, the long pair had two discrete clusters whereas the short pair only one signal (Fig. 5a). These differences suggest chromosomal rearrangements. Sometimes the rDNA cluster was on the shortest bivalent (Fig. 4a). The rDNA signal on the long chromosome of I. pavelii and I. modestior, or short one of I. longicaudata adamovici, also varied in size (Table 1 - see the chromosome number marked with an asterisk). In I. rhodopensis (some popula- 

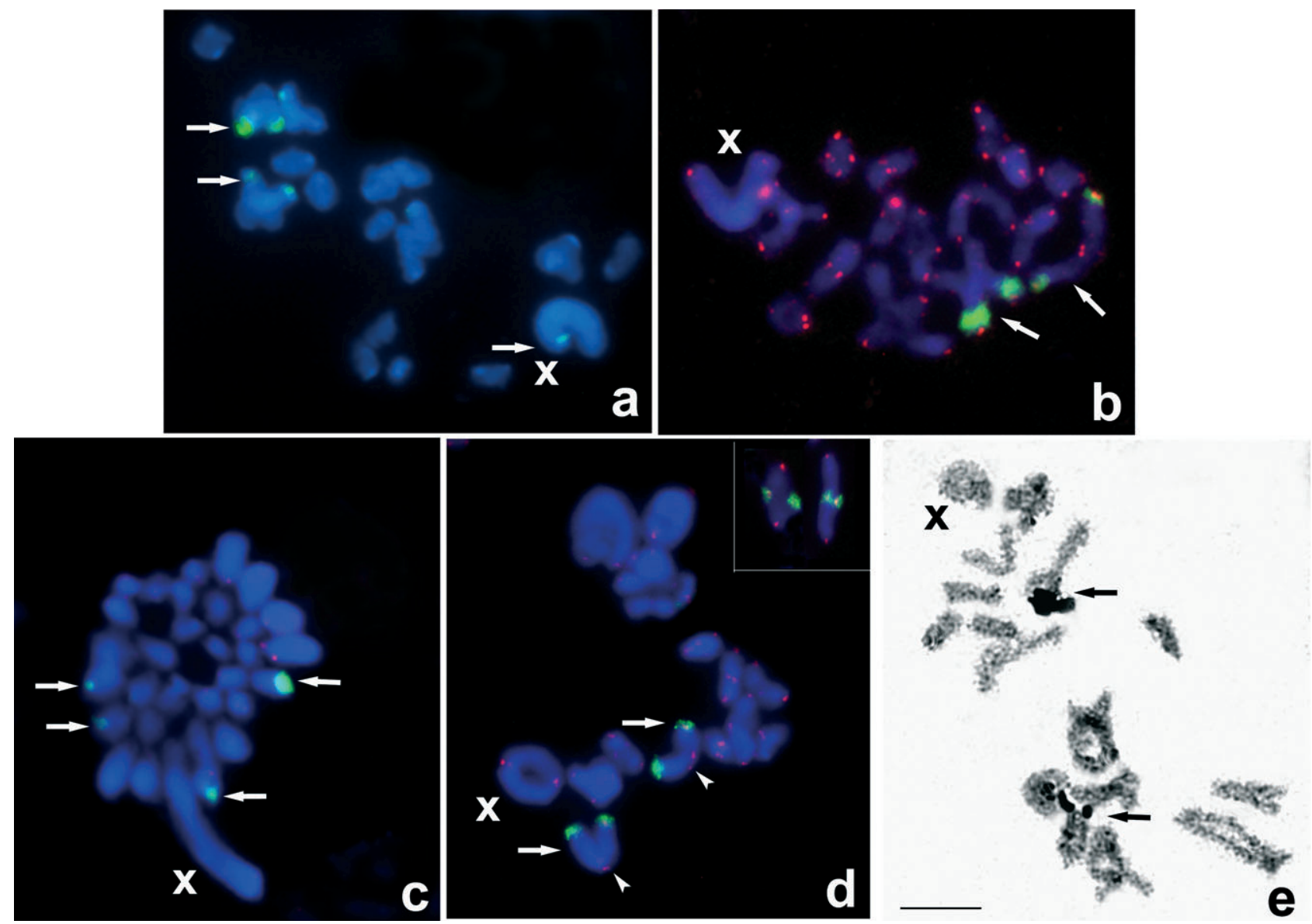

Fig. 2. Diplotene (a) in I. pavelii with rDNA signals and (b) in I. modestior FISH, using both the 18S rDNA (green) and telomeric DNA (red) probes. Arrows indicate ( $a, b)$ rDNA sites in centromeric regions on two long bivalents (probably $\mathrm{L}_{1 / 2}, \mathrm{~L}_{3 / 4}$ ) and (a) a low intensity site on the X chromosome. Spermatogonial mitotic metaphase (c) and (d) diplotene in I. rectipennis from the Sliven population using both the $18 \mathrm{~S}$ rDNA and telomeric probes; arrows indicate rDNA clusters on probably $\mathrm{L}_{4}$ and $\mathrm{M}_{5}$ bivalents distal to the centromere (arrowheads), with (d) terminal or (in the right corner) interstitial chiasmata; (e) silver-stained diplotene with two active NORs (arrows). TTAGG signals in (c) and (d) are weak. Bar $=10 \mu \mathrm{m}$.

tions) and I. bureschi, the rDNA-FISH signal was not observed on one of the homologous chromosomes (Figs 1b, 5b) (Table 1 - marked with two asterisks).

The present analysis of the locations of active NORs was not always congruent with the results of Warchałowska-Śliwa et al. (2008). These differences probably result from the lower number of cells analyzed by Warchałowska-Śliwa et al. (2008), leading to an imprecise determination of the size of the NOR bearing chromosome and/or inability to detect the very small AgNORs on some chromosomes. In the present study, both the NOR activity and rDNA-FISH pattern were always recorded on meiotic bivalents at prophase I of the same individuals of each species. In most of the species analyzed, FISH signals were coincident with the active NORs visualized by $\mathrm{AgNO}_{3}$ staining (Table 1 and Figs 2e, $3 c, 4 c)$. However, a lack of full congruency between the location of rDNA and NOR activity was recorded for the $\mathrm{X}$ chromosome of $I$. pavelii, the $1 / 2$ autosome of $I$. pienensis, the $12 / 13$ of $I$. tosevski and in some individuals of I. rhodopensis/leonorae (the population from Rodopi Mts, Trigrad-Zhrebevo).
FISH with the (TTAGG) $)_{n}$ probe (tDNA-FISH) was used on the spermatogonial/oogonial mitoses and spermatocyte nuclei at different stages of meiosis. In all Isophya species the FISH signals were detected at the distal ends of most autosomes. Differences in the intensity of hybridization signals were detected among most of the autosomes of each species and on the X chromosome of some species (Fig. 5c-f). Generally, the tDNA-FISH signals on chromosomes of I. altaica, I. plevnensis or I. rectipennis (Fig. 2c, d) were weaker than on those of $I$. gulae, I. leonorae, I. modestior and I. camptoxypha (Figs $2 b, 3 b)$. tDNA-FISH signals were recorded on the centromeric regions of subacro/submetacentric X chromosomes. The telomeric FISH signals on this chromosome differed in most of the species.

\section{DISCUSSION}

The present study focused on the evolution of the karyotype in Isophya by mapping the location of rRNA coding genes on chromosomes using FISH and using silver staining $\left(\mathrm{AgNO}_{3}\right)$ to evaluate the activity of rDNA clusters. These markers were used in an attempt to 

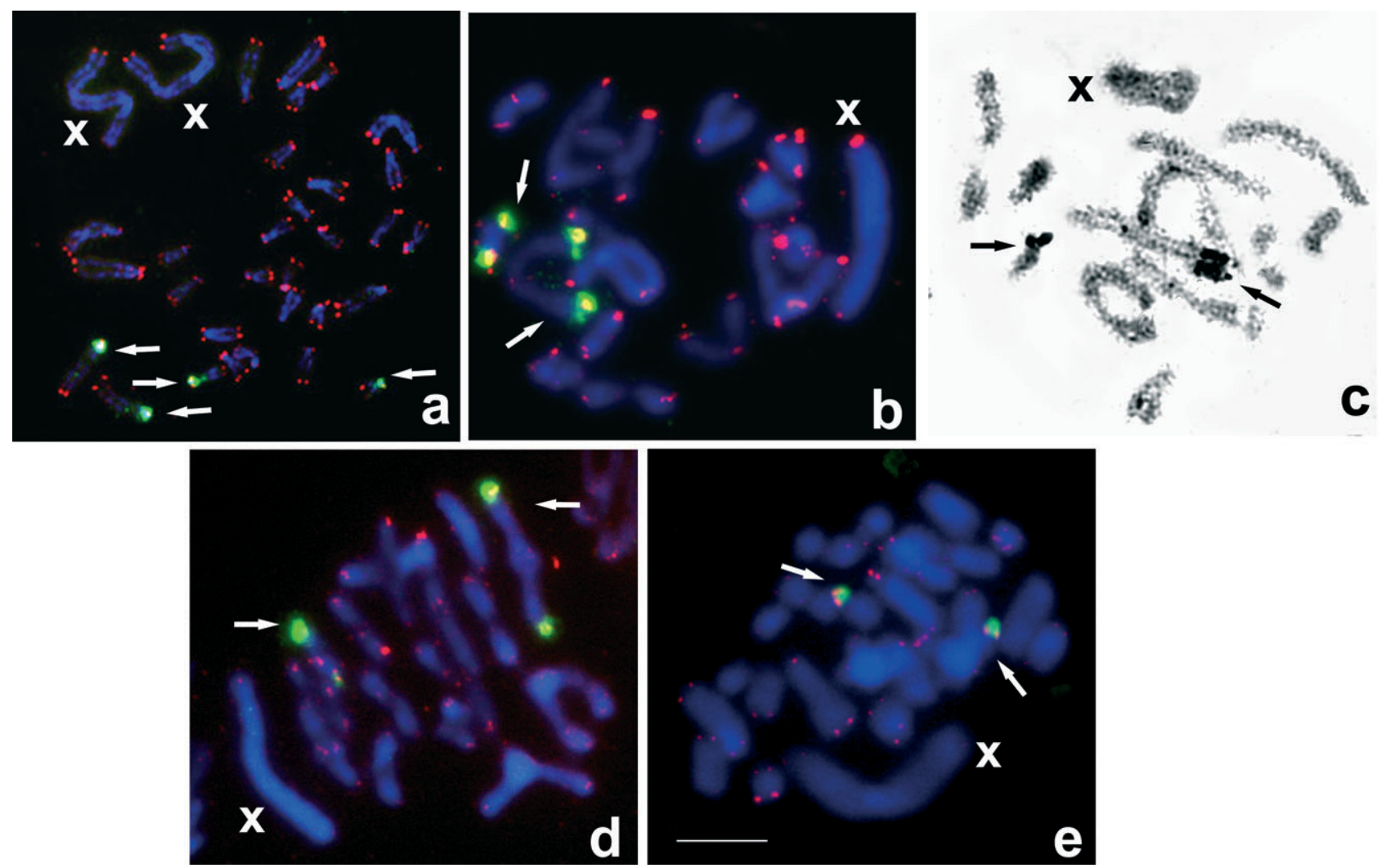

Fig. 3. FISH using both the $18 \mathrm{~S}$ rDNA (green) and telomeric DNA (red) probes (a, b, d, e). (a) Mitotic metaphase of a female of $I$. altaica and (b) diakinesis in I. camptoxypha with rDNA signals near the centromeric regions (arrows) on one long (3/4) and one short pair of chromosomes (11/13); (c) silver-stained diplotene in I. camptoxypha with two active NORs (arrows). (d) Diplotene and (e) spermatogonial mitotic metaphase in I. bureschi with intra-specific polymorphism; rDNA cluster on (d) two bivalents (population Rila Mts) and (e) only on one short chromosome (population from Sashtinska Sredna Gora Mt.). TTAGG signals in (e) are weak. Bar $=10 \mu \mathrm{m}$.

improve the characterisation of the chromosomes and compare the cytogenetic features of this genus.

rDNA-FISH patterns vary among the Isophya species in terms of the number of signals and sizes of chromosomes bearing the $18 \mathrm{~S}$ rDNA cluster. Quantitative analysis of data (Table 1) showed that the number of autosomes (within the haploid genome) bearing rDNA clusters were two (in 15 species), exceptionally one (only in two populations of I. bureschi) and rarely three to five (6 species). Comparative analysis of the location of rDNA among individuals from two or more geographical populations of the same species demonstrated the same FISH signals in I. speciosa, I. miksici and I. petkovi. On the other hand, the number of $18 \mathrm{~S}$ rDNA sites detected in populations and/or individuals of I. bureschi, I. rhodopensis and I. rhodopensis/leonorae varied from one to two in I. bureschi or three to five and two to five in the Rhodopean specimens of I. rhodopensis and I. rhodopensis/leonorae, respectively.

With respect to other Tettigoniidae so far analyzed, the chromosome complement of Isophya shows an unusually high number of active NORs. For example in most Tettigoniinae (see Warchałowska-Śliwa et al., 2005) and Saginae (Warchałowska-Śliwa et al., 2009) the active NOR with rDNA loci is located only on a single bivalent. In the African species Lunidia viridis (Phaneropteridae) a cluster of rDNA repeats corresponding to an active NOR occur on a single large bivalent (Hemp et al., 2010). The increased number of autosomes bearing NORs and/or the varied location of these regions on the chromosomes of some Isophya species should be considered as a derived state caused by unknown chromosome rearrangements. The inter-specific and intra-specific variation in the chromosomal location of rDNA (analyzed using FISH) and NOR activity (using Ag-NOR staining) could be explained by different mechanisms: either structural chromosomal rearrangements such as translocations or inversions, ectopic re-combinations (e.g. Nguyen et al., 2010), or transposition of rDNA repeats to new locations (see Cabrero \& Camacho, 2008). In most species of Isophya the rDNA loci were located near the centromeric region, with the exception of I. rectipennis in which $18 \mathrm{~S}$ rDNA sites were distally located. Most probably, this species exemplifies a small rearrangement in two long chromosomes resulting from a paracentric inversion that changed the position of the rDNA loci. In some species with rDNA loci situated on long or short autosomes, the size of the positive FISH fluorescent signals varied between homologous arms (e.g. Figs 3d, 5b). The latter suggests the existence of polymorphism in the number of rDNA transciptional units. Rearrangements such as translocations between homologous and non-homologous chromo- 

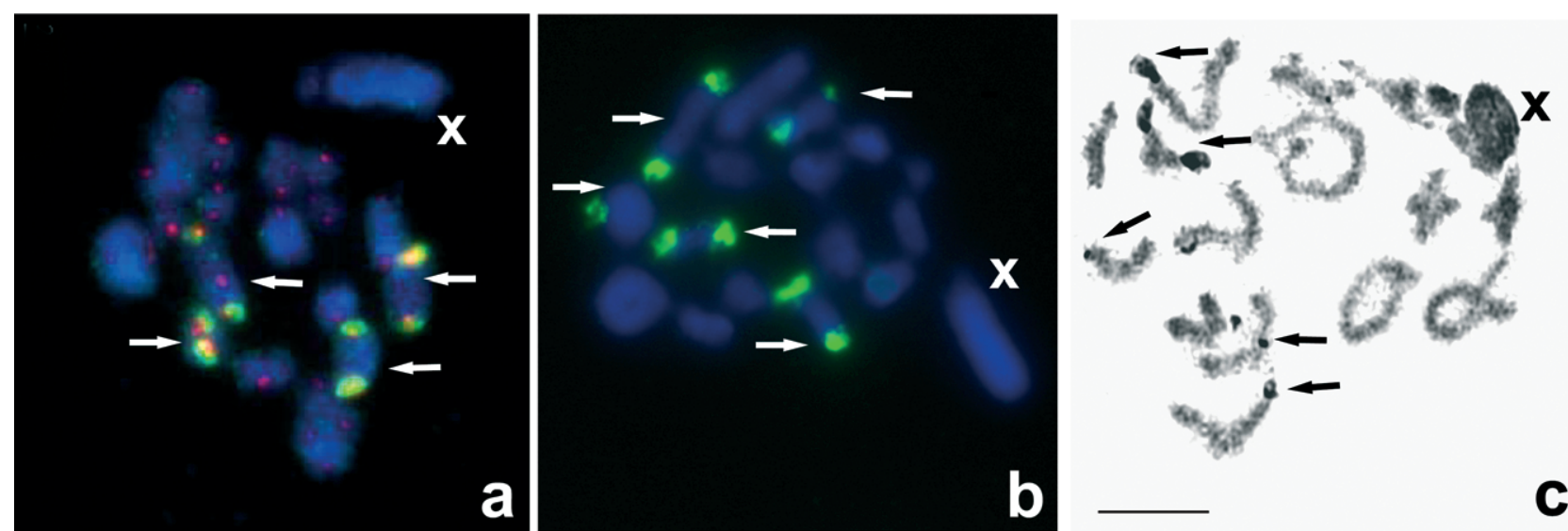

Fig. 4. rDNA-FISH signals (green; arrows) at diakinesis on (a) four bivalents of $I$. petkovi that differ in size and (b) five bivalents of I. leonorae near the centromeric region; (c) silver-stained diplotene in I. leonorae with five active NORs (arrows). Bar $=10 \mu \mathrm{m}$.

somes or duplication of loci by unequal crossing-over probably resulting in different numbers of copies of homologous chromosome, could be implicated by the heteromorphic FISH signal (e.g. Boroń et al., 2006).

The rDNA was frequently on a long chromosome (3/4) in all Isophya species and this is probably a plesiomorphic state for these taxa. On the other hand, a short chromosome (probably 11/13) was usually the characteristic location in species belonging to the second and third groups (Table 1). Only I. pavelii showed an extra inactive cluster of rDNA near the centromeric region of the $\mathrm{X}$ chromosome. It is more likely that this cluster is a result of rDNA spread than a remnant of a NOR lost in other species due to fast divergence of the $\mathrm{X}$ chromosome. Although, there are differences in the rates of differentiation between sex chromosomes and the autosomes after hybridization between closely related grasshoppers (Gosálvez et al., 1997; Bridle et al., 2002).

In most orthopterans studied so far, the active NORs are usually located in the constitutive heterochromatin (e.g. Cabrero \& Camacho, 1986; Marchi \& Pili, 1994;
López-León et al., 1999; Warchałowska-Śliwa et al., 2005). In accordance with this pattern, the rDNA clusters in Isophya are located in the same chromosome regions in which mostly thick, heterochromatic $\mathrm{C}$-positive bands are present (Fig. 1a, b; see also Warchałowska-Śliwa et al., 2008), probably composed of multiple repetitive DNA sequences. Silver staining was used to evaluate the activity of rDNA clusters. However, it is known, that the conventional silver staining method is sometimes unspecific. It is generally used to reveal only active major ribosomal genes, but in some case, it also detects genomic features other than NORs, thus producing false positive results (Dobigny et al., 2004). The pattern of rDNA hybridization has advantages over classical cytogenetic methods; it is highly specific and moreover, may contribute valuable additional information on homologies between chromosomal segments.

In Isophya the number and chromosomal locations of NORs detected in the first meiocytes indicate substantial, although incomplete coincidence between FISH and $\mathrm{AgNO}_{3}$ results. Thus, not all rDNA clusters detected by
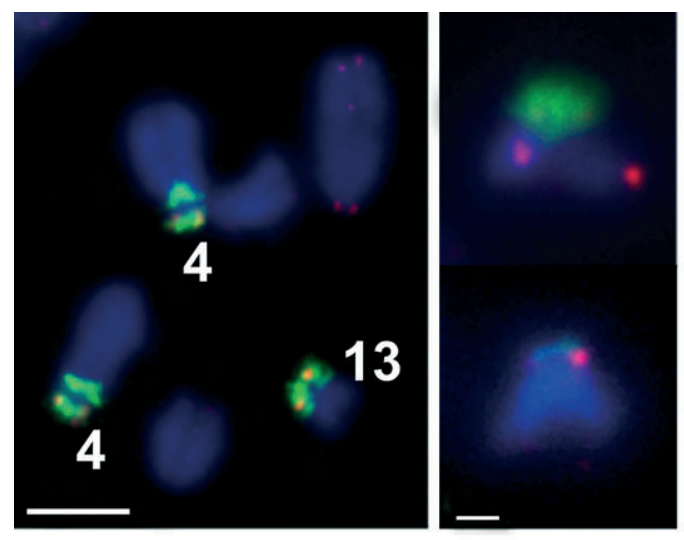

a

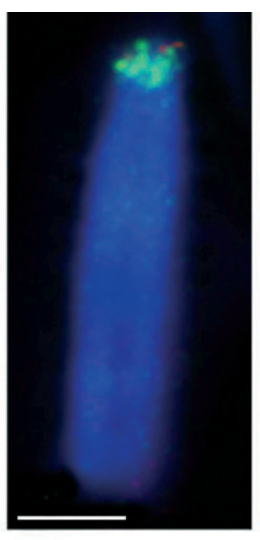

b

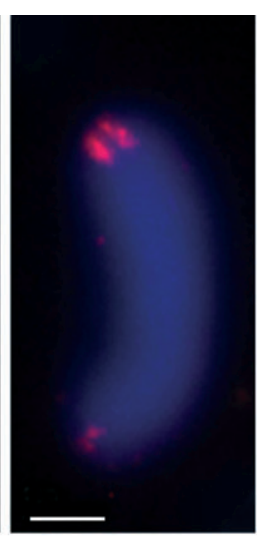

C

d
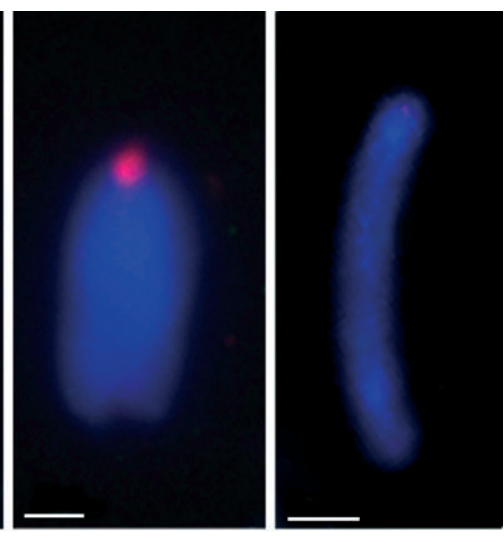

e f

Fig. 5. Differences in intensity of the hybridization signals on Isophya chromosomes after FISH with 18S rDNA (green) and telomeric DNA probes (red). Hybridization areas varied in size (a) between autosomes in I. camptoxypha and (b) homologous chromosomes in I. bureschi; $\mathrm{c}-\mathrm{f}$ - the X chromosome of the male; (c) FISH using both the 18S rDNA (green) and telomeric DNA (red) probes in I. pavelii; differences in the intensity of the tDNA signals (d) in I. camptoxypha, (e) I. andreevae and (f) I. toshevski. Bars $=1 \mu \mathrm{m}(\mathrm{a}-\mathrm{d}, \mathrm{f})$ and $2 \mu \mathrm{m}(\mathrm{e})$. 
FISH are active during meiosis (i.e. form nucleoli). This is probably connected with inactive rDNA loci on the $\mathrm{X}$ chromosome of I. pavelii, on one of the long autosomes of I. pienensis and in one I. bureschi individual. Similar to our results, the combined use of FISH and silver impregnation methods reveals the existence of inactive rRNA genes in some species of grasshoppers (e.g. LópezLeón et al., 1999; Cabrero \& Camacho, 2008). So, as shown by silver impregnation in Isophya species not all rDNA clusters detected by FISH are active during meiosis and the present analysis of the location of active NORs is not completely congruent with the results of Warchałowska-Śliwa et al. (2008). Also the fact that the individual NOR-bearing chromosomes could not be identified weakens the usage of rDNA/NOR as a marker for determining phylogenetic relationships between Isophya species. The significance of rDNA clusters when chromosome homologies are not identified in evolutionary studies are critically discussed by Dobigny et al. (2004).

The terminal locations of hybridization signals in Isophya showed that the telomeres are composed of (TTAGG) $)_{n}$ repeats, as in other orthopterans (e.g. LópezFernández et al., 2004; Warchałowska-Śliwa et al., 2009; Hemp et al., 2010). Differences in the intensity of the hybridization signal detected among some autosomes and $\mathrm{X}$ chromosomes between species may be related to the presence of a different number of repeats of ribosomal sequences. However, for a precise comparison, an analysis with measurement of signal intensity is necessary. On the other hand, the lack of tDNA-FISH signals could probably be due to a low copy of telomeric repeats, insufficient for detection by the standard FISH technique (Cabrero et al., 2007; Warchałowska-Śliwa et al., 2009).

A high level of genetic polymorphism was detected within the genus Isophya by using RAPD (Random Amplification of Polymorphism DNA) markers (Grzywacz \& Warchałowska-Śliwa, 2008) and four DNA fragments - two mitochondrial (cytochrome oxidase II COII, cytochrome b - cytb) and two nuclear sequences (internal transcribed spacer I and II - ITS1, ITS2) (Grzywacz-Gibała et al., 2010). These results show some conflict with the systematics of the group based on morphological and bioacoustic data and represent only the first step in the reconstruction of the phylogeny of Isophya.

The first mapping of the chromosomal location of $18 \mathrm{~S}$ ribosomal genes revealed variability among the Isophya species and partly corresponded to the morphological groupings proposed in earlier studies (e.g. Warchałowska-Śliwa et al., 2008; Chobanov 2009a, b). Six species from the first group (Table 1) based on the localization of the $18 \mathrm{~S}$ rDNA (Table 1) showed a FISH signal only on two long autosomes $(1 / 2,3 / 4)$. These species belong to four morphological groups (after Warchałowska-Śliwa et al., 2008): (1) the most primitive ones belong to the Isophya rectipennis group (I. rectipennis, I. pavelii, etc.), (2) the highly morpho-acoustically specialized schneideri (I. speciosa) group, and (3/4) the costata / kraussii relatives. Species with rDNA loci on one long (3/4) and one short (11-13) chromosome belong to the pyrenaea group (I. gulae, I. obtusa, I. altaica and I. camptoxypha) and partly to the modesta group (after Warchałowska-Śliwa et al., 2008). Furthermore, in the remaining species of the modesta group, the number of autosomes bearing rDNA loci ranged from two to five. The variation observed between and within taxa of the modesta group at the genetic level, including the number of rDNA sites (present paper) and variation in DNA fragments (COII, cytb, ITS1, ITS2) (Grzywacz-Gibała et al., 2010), is higher than the morpho-behavioural diversity known in this group. The great similarities between taxa of this group and observed intra-specific variation suggest the recent evolution of the $I$. modesta relatives (Grzywacz-Gibała et al., 2010). The genetic differences (based both on rDNA markers and DNA fragments) between populations of I. bureschi, I. rhodopensis and I. rhodopensis/leonorae suggest ongoing divergence in isolated or remote populations and probable hybridization in the zones of secondary contact.

In conclusion, the present study has focused on the cytogenetic mapping of rRNA coding genes and telomeric sequences in the genus Isophya. The variation in the number and situation of $18 \mathrm{~S}$ rDNA loci and/or AgNORs in the stable karyotype of this genus are probably important species-group specific phylogenetic markers. Analysis of these markers reveals that the evolutionary dynamics of rDNA in this genus is remarkably high, which is confirmed by changes in the chromosomes bearing signals at inter- and intra-specific levels. Future karyotype analyses using FISH with rRNA gene sequences and telomeric sequences should be carried out on other related genera of Barbitistini to gain a more comprehensive view of chromosome evolution in the Phaneropterinae.

ACKNOWLEDGEMENTS. This research was supported by the Ministry of Science and Higher Education of Poland, grant N N303 611738 to E. Warchałowska-Śliwa \& B. Grzywacz. T. Karamysheva was partially supported by the Mianowski Fund Foundation for the Promotion of Science (2009), Poland, and by the Russian Foundation for Basic Research, grant 08-04-00167. D.P. Chobanov was supported by grants DO $02-259 / 08$ of the Ministry of Education, Youth and Science of Bulgaria, BG051PO001-3.3.04/41 (European Social Fund through the Ministry of Education, Youth and Science of Bulgaria) and the Orthopterists' Society Small Grants Program.

\section{REFERENCES}

Bey-BIEnko G.YA. 1954: Phaneropterinae. Fauna of the USSR. Orthoptera 2(2). Zoological Institute of the Academy of Sciences, Moscow-Leningrad, $385 \mathrm{pp}$.

Boroń A., Porycka K., Ito D., Abe S. \& Kirtiklis L. 2009: Comparative molecular cytogenetic analysis of three Leuciscus species (Pisces, Cyprinidae) using chromosome banding and FISH with rDNA. Genetica 135: 199-207.

Bridle J.R., De la Torre J., Bella J.L., Butlin R.K. \& GósALVEz J. 2002: Low levels of chromosomal differentiation between the grasshoppers Chorthippus brunneus and Chorthippus jacobsi (Orthoptera; Acrididae) in Northern Spain. Genetica 114: 121-127. 
Cabrero J. \& CAMacho J.P.M. 1986: Cytogenetic studies in gomphocerinae grasshoppers. II. Chromosomal location of active Nucleolar Organizing Region. Can. J. Genet. Cytol. 28: $540-544$.

Cabrero J. \& CAmacho J.P.M. 2008: Location and expression of ribosomal RNA genes in grasshoppers: Abundance of silent and cryptic loci. Chromosome Res. 16: 595-607.

Cabrero J., Gómez R. \& Camacho J.P.M. 2007: No evidence of the presence of Wolbachia in the parthenogenetic insect Saga pedo. Proc. XI. Eur. Soc. Evol. Biol. Congress, Uppsala, Sweden, 20-25 August 2007. Uppsala, p. 277.

Chobanov D.P. 2009a: New records and a new synonym of Orthoptera from Bulgaria. Articulata 24: 79-108.

Chobanov D.P. 2009b: Phylogeny and systematics of the Isophya modesta group (Phaneropteridae) based on morphology and bioacoustics. Metaleptea 28: 20-27.

Dobigny G., Ducroz J.-F., Robinson T.J \& Volobouev V. 2004 Cytogenetic and cladistics. Syst. Biol. 53: 470-484.

Eades D.C., Otte D., Cigliano M.M. \& Braun H. 2011: Orthoptera Species File Online. Version 2.0/4.0. [09.ii.2011]. http://Orthoptera.SpeciesFile.org

Gosálvez J., Mason P.L. \& López-Fernández C. 1997: Differentiation of individuals, populations and species of Orthoptera: the past, present and future of chromosome markers. In Gangwere S.J., Muralirangan M.C. \& Mularirangan M. (eds): The Bionomics of Grasshoppers, Katydids and their Kin. CAB International, Wallingford, pp. 355-383.

Grzywacz B. \& WarchatowsKa-Śliwa E. 2008: Polymorphism of the genus Isophya (Orthoptera, Phaneropteridae, Barbitistinae) revealed by RAPD. Folia Biol. (Kraków) 56: 153-157.

Grzywacz-GibaŁa B., Chobanov D.P. \& Warcha£owsKa-Śliwa E. 2010: Preliminary phylogenetic analysis of the genus Isophya (Orthoptera, Phaneropteridae) based on molecular data. Zootaxa 2621: 27-44.

Harz K. 1969: Die Orthopteran Europas I. Series Entomologica. W. Junk, The Hague, 750 pp.

Hemp C., Heller K.-G., Warchąowska-Śliwa E. \& Hemp A. 2010: Ecology, bioacoustics and chromosome analysis of a new genus and species of African Phaneropterinae (Orthoptera: Tettigoniidae). Org. Divers. Evol. 10: 215-226.

Heller K.-G. 1988: Bioakustik der europäischen Laubheuschrecken. Margraf, Weikersheim, 360 pp.

Heller K.-G. 2006: Song evolution and speciation in bushcrickets. In Drosopoulos S. \& Claridge M.F. (eds): Insect Sounds and Communication. CRC Press, Boca Raton, pp. 137-152.

Heller K.-G., Orci K.M., Grein G. \& Ingrisch S. 2004: The Isophya species of Central and Western Europe (Orthoptera: Tettigonioidea: Phaneropteridae). Tijdsch. Entomol. 147: 237-258.

Lichter P., Cremer T., Tang C.J., Watkins P.C., Manuelidis L.\& WARD D.C. 1988: Rapid detection of human chromosome 21 aberration by in situ hybridisation. Proc. Natl. Acad. Sci. USA 85: 9664-9668.

López-Fernández C., Pradillo E., Zabal-Aguirre M., Fernández J.L., Garcia de la Vega C. \& Gisálvez J. 2004: Telomeric and interstitial telomeric-like DNA sequence in Orthoptera genomes. Genome 47: 757-763.

López-León M.D., CABrero J. \& CAMAcho J.P.M. 1999: Usually high amount of inactive ribosomal DNA in the grasshopper Stauroderus scalaris. Chromosome Res. 7: 83-88.

Loreto V., Cabrero J., Camacho J.P.M. \& Souza M.J. 2008: Comparative analysis of rDNA location in five Neotropical gomphocerine grasshopper species. Genetica 132: 95-101.
Marchi A. \& Pili E. 1994: Ribosomal RNA genes in mosquitoes: localization by fluorescence in situ hybridization (FISH). Heredity 72: 599-605.

Nguyen P., Sahara K., Yoshido A. \& Marec F. 2010: Evolutionary dynamics of rDNA clusters on chromosomes of moths and butterflies (Lepidoptera). Genetica 138: 343-354.

Sahara K., Marec F. \& Traut W. 1999: TTAGG telomeric repeats in chromosomes of some insects and other arthropods. Chromosome Res. 7: 449-460.

Sevgili H. 2003: A new species of bushcricket (Orthoptera: Tettigoniidae) of the Palearctic genus Isophya (Phaneropterinae) from Turkey. Entomol. News 114: 129-137.

Sevgili H. \& Heller K.-G. 2003: A new species of the genus Isophya Brunner von Wattenwyl (Orthoptera: Tetigoniidae: Phaneropterinae). Tijdsch. Entomol. 146: 39-44.

Sevgili H., Çiplak B., Heller K.-G. \& Demisroy A. 2006: Morphology, bioacoustics and phylogeography of the Isophya major group (Orthoptera: Tettigoniidae: Phaneropterinae): A species complex occurring in Anatolia and Cyprus. Eur. J. Entomol. 103: 657-671.

SuMNER S.G. 1972: A simple technique for demonstrating centromere heterochromatin. Exp. Cell Res. 75: 304-306.

WARChA£OWSKA-ŚLIWA E. 1998: Karyotype characteristics of katydid orthopterans (Ensifera, Tettigoniidae) and remarks on their evolution at different taxonomic levels. Folia Biol. (Kraków) 46: 143-176.

WarchalowsKa-Śliwa E. \& Bugrov A.G. 1998: Karyotypes and C-banding patterns of some Phaneropterinae katydids (Orthoptera, Tettigonioidea) with special attention to a postreductional division of the neo- $X$ and the neo- $Y$ sex chromosomes in Isophya hemiptera. Folia Biol. (Kraków) 46: $47-54$.

WarchalOWSKa-ŚLIWA E. \& MaryańSKa-NaDACHOWSKa A. 1992: Karyotypes, C-bands, NORs location in spermatogenesis of Isophya brevipennis Brunner (Orthoptera: Phaneropteridae). Caryologia 45: 83-89.

Warchalowska-Śliwa E., Heller K.-G. \& MaryańsKa-NadaCHOWSKA A. 2005: Cytogenetic variability of European Tettigoniinae (Orthoptera, Tettigoniidae): Karyotypes, C-and Ag-NOR-banding. Folia Biol. (Kraków) 53: 161-171.

Warchąowska-Śliwa E., Chobanov D.P., Grzywacz B. \& MARYAŃSKA-NADAChowsKa A. 2008: Taxonomy of the Genus Isophya (Orthoptera, Phaneropteridae, Barbitistinae): Comparison of karyological and morphological data. Folia Biol. (Kraków) 56: 227-241.

WarchalowsKa-Śliwa E., Grzywacz B., MaryańsKa-Nadachowska A., Karamysheva T.V., Rubtsov N.B. \& Chobanov D.P. 2009: Chromosomal differentiation among bisexual European species of Saga Charp. (Orthoptera, Tettigoniidae, Saginae) detected by both classical and molecular methods. Eur. J. Entomol. 106: 1-9.

White M.J.D. 1973: Animal Cytology and Evolution, 3rd ed. Cambridge Univ. Press, London, 961 pp.

Whiting M.F., Carpenter J.C., Wheeler Q.D. \& Wheeler W. C. 1997: The Strepsiptera problem: phylogeny of the holometabolous insect orders inferred from $18 \mathrm{~S}$ and $28 \mathrm{~S}$ ribosomal DNA sequences and morphology. Syst. Biol. 46: 1-68.

Zacaro A.A., Proença S.J.R, Lopez-Andrade C. \& Serrano A.R.M. 2004: Cytogenetic analysis of Ctenostomini by $\mathrm{C}$-banding and rDNA localization and its relevance to the knowledge of the evolution of tiger beetles (Coleoptera: Cicindelidae). Genetica 122: 261-268.

Received March 15, 2011; revised and accepted June 3, 2011 